\title{
Design and key parameter optimization of an agitated soybean seed metering device with horizontal seed filling
}

\author{
Honglei Jia ${ }^{1,2}$, Yulong Chen ${ }^{1,2}$, Jiale Zhao ${ }^{1,2^{*}}$, Mingzhuo Guo ${ }^{1,2}$, Dongyan Huang ${ }^{1,2}$, Jian Zhuang ${ }^{1,2}$ \\ (1. College of Biological and Agricultural Engineering, Jilin University, Changchun 130025, China; \\ 2. Key Laboratory of Bionics Engineering, Ministry of Education, Jilin University, Changchun 130025, China)
}

\begin{abstract}
Since the low seed filling speed of mechanical seed metering devices reduces the low qualified rate of seed spacing during high-speed practices, it is significant to design agitated seed metering devices with horizontal seed filling that are suitable for high-speed practices. The combination of horizontal seed filling and agitated seed filling can accelerate the seed filling of mechanical seed metering devices, and improve the qualified rate of seed spacing during high-speed practices. In this study, theoretical analysis, discrete element method-based simulation and indoor bench test verification were conducted to investigate how key parameters of the agitated seed metering device with horizontal seed filling (angles, installation position and number of agitating plates, diameters of convex spoons) would affect the characteristics of soybean seed movement, seed number and seeding performance (qualified index, multiple index, missing seeding index) under different working speeds. Computer-based simulation, test design and regression analysis were combined to analyze the population moving rules and optimize the design parameters of seed metering devices. Based on the test scheme as designed, simulations were conducted on Fluent EDEM, and the optimal angle of the agitating plates was determined by analyzing the population migrating rules Regression equations were established through the regression of test results, and used to find out the optimal design parameters (diameter of convex spoon, positions and number of agitating plates) of seed metering devices. Then the optimal parameter combination among different working conditions was determined that the angle, position and number of agitating plates were $30^{\circ}, 24.4 \mathrm{~mm}$, and 13, respectively, and the diameter of convex spoon was $11.0 \mathrm{~mm}$. With the optimal parameter combination and at the seeding speed of $12 \mathrm{~km} / \mathrm{h}$, the qualified index, multiple index and missing seeding index were $93.1 \%, 2.1 \%$ and $4.8 \%$, respectively. Under high-speed practices, the new seed metering device was not significantly different from the pneumatic seed metering device, but significantly outperformed the mechanical seed metering device.
\end{abstract}

Keywords: soybean seed metering device, horizontal seed filling, agitated seed filling, high-speed precision seeding, discrete element method

DOI: $10.25165 /$ j.ijabe.20181102.3464

Citation: Jia H L, Chen Y L, Zhao J L, Guo M Z, Huang D Y, Zhuang J. Design and key parameter optimization of an agitated soybean seed metering device with horizontal seed filling. Int J Agric \& Biol Eng, 2018; 11(2): $76-87$.

\section{Introduction}

High-speed precision seeding is defined such that a high-speed precision seed metering unit is used to rapidly sow at consistent row spacing and uniform seed spacing and accurately localize the seeding positions while the seeding density satisfies agronomic requirements ${ }^{[1-4]}$. Because of its cost-saving advantage, high-speed precision seeding has become the most important seeding technique in modern agricultural technology systems ${ }^{[5-8]}$. The working quality of high-speed seeding is mainly decided by the performance of the high-speed precision seed metering device $^{[9-11]}$, but the adaptation of the device to high-speed seeding

Received date: 2017-05-01 Accepted date: 2018-02-16

Biographies: Honglei Jia, Professor, research interests: conservation tillage technique and full-course mechanization, Email: jiahl@vip.163.com; Yulong Chen, $\mathrm{PhD}$ candidate, research interests: conservation tillage technique, Email: 17743125073@163.com; Mingzhuo Guo, PhD candidate, research interests: conservation tillage technique, Email: guomingzhuo@outlook.com; Dongyan Huang, PhD, Professor, research interests: conservation tillage technique, Email: cchdy760829@sina.com; Jian Zhuang, PhD, research interests: conservation tillage technique, Email: zhuangjian_2001@163.com.

*Corresponding author: Jiale Zhao, PhD, Lecturer, research interests: conservation tillage technique and agriculture mechanization design. College of Biological and Agricultural Engineering, Jilin University, No.5988 Renmin Street, Changchun 130025, China. Tel: +86-18843165417; Email: zhaojiale0313@163.com. is mainly decided by its seed filling speed ${ }^{[12,13]}$. Thus, designing high-performance high-speed precision seed metering devices is the premise and basis that guarantee the working quality of high-speed precision seeding ${ }^{[12,14]}$.

Seed metering devices are mainly divided into mechanical ${ }^{[15-17]}$ and pneumatic types ${ }^{[12,18,19]}$. The seed filling of a pneumatic seed metering device is mainly dependent on air suction ${ }^{[18,20]}$, and its seed filling rate during high-speed practices can be accelerated by improving the suction force. Thus, high-speed seeding workers mostly adopt pneumatic seed metering devices. For instance, the Gaspardo pneumatic soybean seed metering device designed by Maschio reaches the qualified index of $95 \%$ under the working speed of $10 \mathrm{~km} / \mathrm{h}^{[19]}$. However, the application of pneumatic seed metering devices is still limited by the structural complexity and high purchase and maintenance costs ${ }^{[12,14]}$. The seed filling of a mechanical seed metering device is mainly by means of the gravity of seeds, interaction between seeds, or clamping force of the seed clamping unit, which account for the low seed filling speeds ${ }^{[9,17]}$. Thus, mechanical seed metering devices guarantee high seeding efficiency under medium- and low-speed practices. For instance, the vertical-disc hole-typed soybean seed metering device developed by Kinze reaches a seeding qualified index above $90 \%$ under the working speed of $8 \mathrm{~km} / \mathrm{h}$, but its qualified index of seed spacing under high-speed practices is low ${ }^{[21,22]}$.

Northeast China, the largest commodity grain base of China, 
produces $42 \%$ of soybeans in China, but this region is relatively undeveloped and unable to devote large capitals into agricultural production. At present, the precision seeding speeds in Northeast China vary largely between $4-12 \mathrm{~km} / \mathrm{h}^{[2,3,23]}$. The most-used type of seeding devices here is mechanical seed metering devices, because pneumatic seed metering devices are limited by high manufacture and maintenance costs and they are unable to perform well under low-speed practices. Thus, in this study, an agitated seed metering device with horizontal seed filling was designed for high-speed practices. The combination of horizontal seed filling and agitated seed filling raised the seed filling speed above that mechanical seed metering devices, and improved the qualified index of seed spacing during high-speed practices. Also discrete element method-based simulation and indoor platform verification tests were conducted to study how key parameters of this agitated seed metering device (angles, installation position and number of agitating plates; diameters of convex spoons) would affect the characteristics of soybean seed motions and the seeding effect. The optimal parameter combination among different working conditions was determined, which broke through the limitations of high-speed practices and was suitable for low, medium and high-speed seeding practices.

\section{Materials and methods}

\subsection{Agitated seed metering device}

\subsubsection{Structure and working principle}

The agitated seed metering device with horizontal seed filling consists of a seed collecting disc, partition, a seed metering shaft, agitating plates, a seed transport disc, flange, and shell (Figure 1). In particular, the flange is fixed by the cylindrical pin onto the shaft, while the collecting disc is bolted onto the flange. The transport disc is bolted to the collecting disc, and the two discs are separated by a gap with the same thickness of the partition. The partition is clipped in between the two discs, and its circumferential rotation is restricted by the spacing hole device, which is mounted on the chucking lug and the shell. The driving force, through the sprocket, drives the shaft to rotate, and the shaft drives the flange and the two discs to rotate together, while the partition is motionless.

The work of an agitated seed metering device with horizontal seed filling is divided into five phases: agitated horizontal seed collection, seed clearing, lateral seed filling, seed transport, and seed dropping. The seeds were delivered into the inner chamber of the seed metering device through the inlet at the upper of the shell. The road wheels transmitted the driving force through the sprocket onto the shaft. The horizontal seed filling disc and the seed transport disc synchronously rotated following the shaft. When the convex spoon of the horizontal seed filling disc revolved off the seeds, the joint action of gravity, pressure of agitating plates, between-seed collision and friction, supporting force from the spoon, and agitating plates would drive the seeds to move inside the spoon. After that, seed collection was finished. When the spoon carried the seed away from other seeds, due to the variation of force directions, the seeds suspended at the spoon mouth fell down gravitationally. Thereby, only one seed was left in the spoon. So far, seed clearing was finished. The collected seed went on rotation upwards following the collecting disc. When it approached the seed delivering mouth on the partition, it was axially filled. Then the seed transport disc and the horizontal seed filling disc rotated synchronously. Through the seed delivering hole on the partition, the seed fell into the transport hole on the transport disc, which corresponded to the spoon. In the seed transport hole, the seed rotated along with the transport disc. After that, seed transport was finished. When the seed transport hole rotated to the seed dropping mouth, the seed under the joint action of gravity and centrifugal force would depart from the seed metering device. After that, seed dropping was finished.
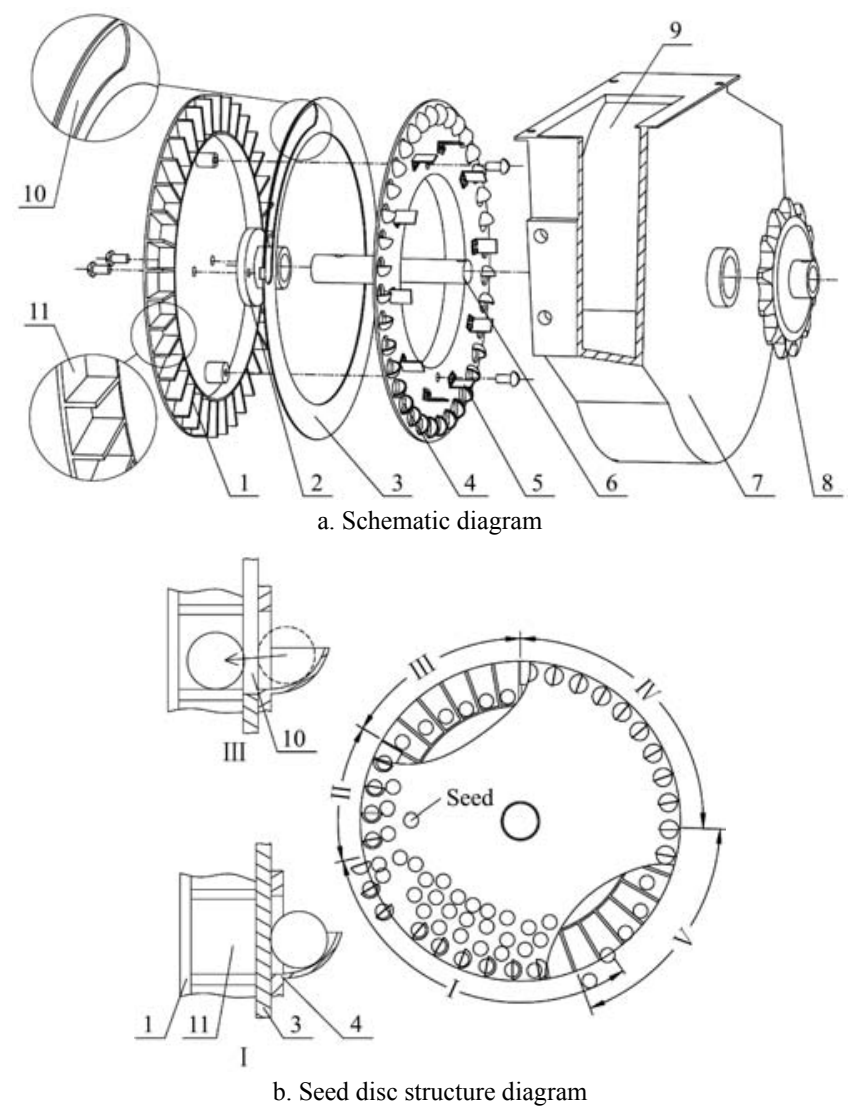

1. Seed transport disc 2. Flange 3. Partition 4. Seed filling disc 5. Agitating plate 6. Shaft 7. Shell 8. Sprocket 9. Inlet 10. Seed delivering hole 11. Seed transport hole I. Seed collection II. Seed clearing III. Lateral seed filling IV. Seed transport V. Seed dropping

Figure 1 Agitated seed metering device with horizontal seed filling

\subsubsection{Horizontal seed filling disc}

The core part of the seed metering device is the horizontal seed filling disc (Figure 2), which is responsible for the seed collection, seed clearing and a part of seed transport. The margins of the horizontal seed filling disc were evenly distributed by convex spoons. As the functional unit of seed collection, the convex spoons were protruding outside of the horizontal seed filling disc. During seed collection, the seeds moved along the tangent direction of the seed metering disc and entered the convex spoons. The inner parts of the convex spoons were opened with shaped-holes, whose width was equal to the inner diameter of the convex spoons. During seed filling, the seed entered the space formed between the convex spoon and the shaped-hole.

The seed filling process by a machinery shaped-hole seed metering device is shown in Figure 3a. Clearly, the conditions for successful filling of soybean seeds are that: when a seed leaves the front walls of the shaped-hole via the horizontal direction to the posterior walls, half of the seed at the vertical direction gets inside the shaped-hole.

$$
v_{1}=\frac{D_{1}-0.5 d}{\sqrt{d \cdot g^{-1}}}
$$

where, $v_{1}$ is the linear velocity of the traditional seed filling disc, 
$\mathrm{m} / \mathrm{s} ; D_{1}$ is the diameter of the shaped-hole, $\mathrm{mm} ; d$ is the diameter of soybean seeds, mm.

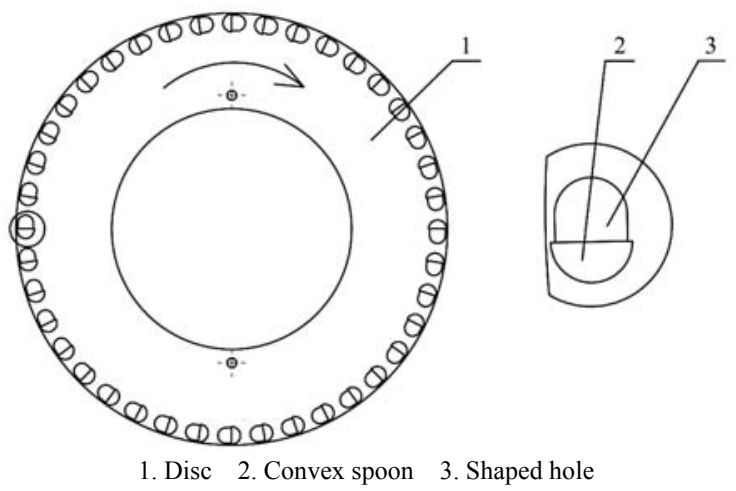

Figure 2 Schematic map of the horizontal seed filling disc

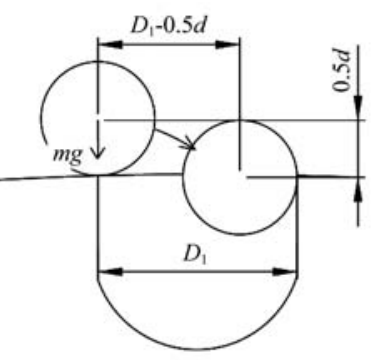

$$
V_{1} \leftarrow
$$

a. Traditional machinery shaped-hole seed metering device

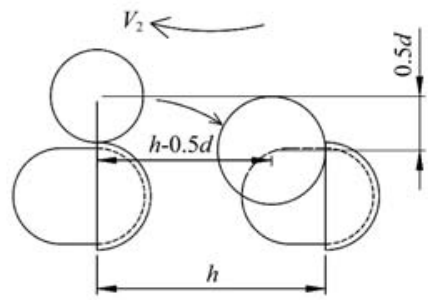

b. Seed metering device with horizontal seed filling
Figure 3 Analysis of seed filling

The seed filling disc was endowed with a high $v_{1}$ to accelerate the seed filling of the high-speed seed metering device. According to Equation (1), to improve the linear velocity of the seed metering device, the seed filling rate should be guaranteed by improving the shaped-hole diameter, which in turn would increase the frequency of repeated seeding under low-speed practices.

The seed filling process by our seed metering device is shown in Figure 3b. Clearly, the conditions for successful filling of soybean seeds are that: when a seed leaves from the front walls of the convex spoon via the horizontal direction to the posterior walls, half of the seed at the vertical direction gets inside of the convex spoon.

$$
v_{2}=\frac{h-0.5 d}{\sqrt{d / g}}
$$

where, $v_{2}$ is the linear velocity of the horizontal seed filling disc, $\mathrm{m} / \mathrm{s} ; h$ is the space between the convex spoons, $\mathrm{mm}$.

According to Equation (2), the seed filling velocity can be improved by only enlarging the between-spoon distance, which, together with the condition of invariable spoon diameter, would prevent repeated seeding under low-speed practices. The relationships among the working velocity, between-spoon distance, diameter of seed metering devices, and number of convex spoons could be determined from Equations (3)-(5).

$$
\begin{gathered}
v_{2}=\frac{\pi D_{2} / k-0.5 d}{\sqrt{d / g}} \\
n=\frac{v_{2} \cdot 60}{\pi \cdot D_{2}} \\
V_{1}=n k s=\frac{\pi D_{2} / k-0.5 d}{\sqrt{d / g}} \cdot 60 \mathrm{ks} /\left(\pi D_{2}\right)
\end{gathered}
$$

where, $V_{1}$ is the working velocity, $\mathrm{km} / \mathrm{h} ; D_{2}$ is the diameter of seed filling disc, $\mathrm{mm} ; n$ is the rotational speed, $\mathrm{r} / \mathrm{min} ; s$ is the seed space ( $s=0.1 \mathrm{~m}$ here); $k$ is the number of convex spoons.

To guarantee the working speed should be above $12 \mathrm{~km} / \mathrm{h}$ and given the factors such as structure sizes, the designing parameters of the horizontal seed filling disc were found to be $D_{2}=240 \mathrm{~mm}$ and $k=40$.

\subsubsection{Agitating plates}

During high-speed seeding, besides the reasonability in designing a horizontal seed filling disc, the seed filling rate of the seed metering device is significantly affected by the seed falling speeds. For a traditional shaped-hole seed metering device, the seed falls into the shaped-hole due to the joint action of gravity, between-seed pressure, and between-seed friction. The falling acceleration $a_{1}$ was determined as follows:

$$
a_{1}=\frac{m g+F^{\prime}-f}{m}
$$

where, $m$ is the seed mass; $F^{\prime}$ is the between-seed pressure; $f$ is the between-seed friction.

Here a new seed metering device was designed by adding agitating plates, which increased the seed falling acceleration. During the sowing, the seed was affected by the pressures imposed by the agitating plates, and its falling acceleration was determined as follows:

$$
a_{2}=\frac{m g+F^{\prime}-f+F}{m}
$$

where, $a_{2}$ is the seed falling acceleration; $m$ is the seed mass; $F$ is the pressure imposed by the agitating plate.

According to Equations (6) and (7), the addition of agitating plates improved the acceleration of the seed and shortened the seed filling time, which accelerated the machinery practices under the premise of ensuring a high seed filling rate.

As shown in Figure 4, on the velocity vector graph of the seeds in the seed metering device, when the device moved at a constant speed, the seed in the seed filling area flew in a half-moon shape, forming four zones: an ascending zone, a collapse zone, a stationary zone, and a reflux zone. When the convex spoon penetrated through the bottom of the seeds, the spoon drove and forcefully took away the bottom seed layer, forming an ascending zone. When the joint action of between-seed friction and drag was reduced to nearly zero, a part of the seeds became relatively motionless, forming a motionless zone. When the seeds rotated along with the horizontal seed filling disc, the seeds in the ascending zone moved to the highest point of the seeds. Since the forced directions of the seeds were changing, all seeds rapidly fell down (except one seed in the spoon that went on moving upwards), forming a collapse zone. The falling seeds returned to the upper surface of the seeds, and moved in the opposite direction of the ascending zone, forming a reflux zone. In this zone, the seeds finally approached the starting point of the ascending zone, so the whole seed group formed a reflux.

The convex spoon only contacted with the seeds in the ascending zone when passing through the seeds, so seed filling only occurred in this zone. For a higher seed filling speed, the seed motion in the ascending zone and the reflux in the reflux zone should be both accelerated. The new agitating plate was installed on the horizontal seed filling disc and rotated at the same speed as this disc. The agitating plate should act on the ascending zone and accelerate the upward movement of the seeds. The agitating plate did not directly promote the falling of the seeds in the reflux zone. Thus, the agitating plate should be installed in the 
ascending zone, or in the motionless zone, so the seeds in the motionless zone would move upwards to the ascending zone, which enlarged the ascending zone and narrowed the motionless zone. This would accelerate the ascending speed in the ascending zone and the falling velocity in the reflux zone. The angle, position and number of the agitating plates all could affect the motion status of the seeds. As shown in Figure 5, agitating plates were designed at three angles, and discrete element method (DEM) was used to simulate how agitating plates would affect the seed velocity and the qualified rate.

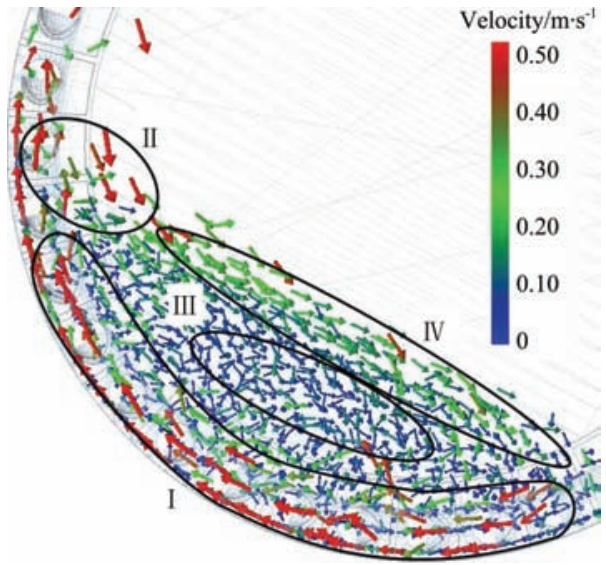

I. Ascending zone II. Collapse zone III. Relatively motionless zone IV. Reflux zone

Figure 4 Schematic map of the seeds

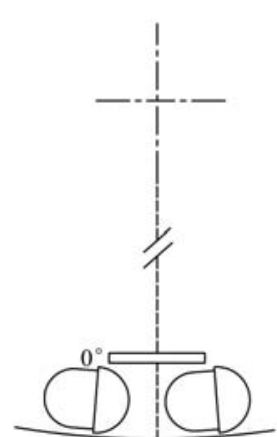

I

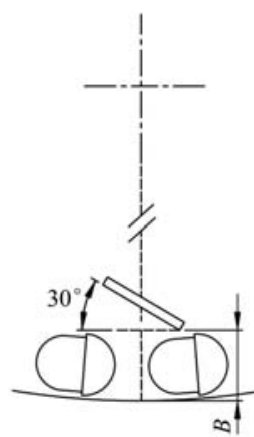

II

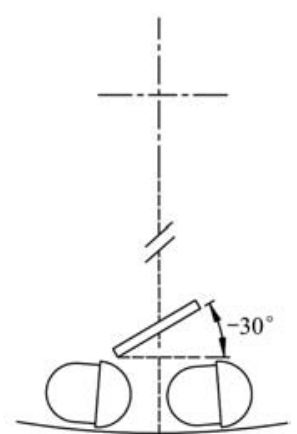

III
Figure 5 Schematic map of angles of agitating plates

\subsection{Test methods}

The tests consisted of three parts. Based on the test scheme designed here, computer-based simulation and regression analysis were combined to optimize the parameters of seed metering structures, each test repeated 5 times for ANOVA analysis. In the first part, as for the single-factor 3-level tests about the angles of agitating plates, the population migration under different conditions was simulated on the DEM software EDEM. The evaluation criterion was that: the instantaneous speed of seeds in the ascending zone was large and stable, and the number of seeds in the ascending zone was large and less fluctuating. Based on this criterion, the optimal angle of agitating plates was determined. In the second part, as for the 3-factor 3-level tests (diameter of convex spoon, positions of agitating plates, number of agitating plates), the scheme as-designed was used to simulate the seed metering process on EDEM. The test results were assessed via analysis of variance (ANOVA), and thereby regression equations were established. These equations were used to determine the optimal design parameters of seed metering devices (angle of agitating plates, diameter of convex spoon, positions and number of agitating plates). In the third part of comparative verification tests, the corresponding seed metering devices were produced based on the above optimal parameter combinations. On the seed metering test bed, the performances of the novel seed metering devices were compared with the mechanical seed metering devices and traditional gas-absorption-typed seed metering devices.

The test data were processed on MATLAB. The effects of test factors on the performances of seed metering devices were evaluated via ANOVA. The $0.05<p, 0.01<p<0.05,0.001<p<0.01$ and $p<0.001$ were considered as insignificant, significant, very significant, and extremely significant, respectively. The data were further regressed to find out the regression equations.

2.2.1 DEM simulation

Here DEM simulation and platform verification tests were combined.

The DEM-solutions EDEM 2.6 was used here. This software consisted of three modules: pre-processing module, simulation module and post-processing module. In the first module, the user could set simulation parameters, geometric model, particle model, particle manufactory and other parameters. In the second module, the user could set simulation step length, time and other parameters and conduct simulation. In the third module, the user could analyze the simulation results and output particle motion speed, orbit, energy and other data.

The seed metering devices were simulated on EDEM by using a Hertz-Mindlin no-slip contact model ${ }^{[22,24]}$. The setting of global parameters is shown in Table 1. The simulation tests consisted of two parts. First, the effects of agitating plate angles on the seed velocity were analyzed. Secondly, the optimal parameter combination was determined, with test factors (position and number of agitating plates; radius of convex spoons) and test indices (qualified index $Q F I$, missing seeding index $M I S$, multiple index $M U L)$.

Table 1 Parameters used in simulation ${ }^{[24]}$

\begin{tabular}{clc}
\hline Name & \multicolumn{1}{c}{ Property } & Value \\
\hline \multirow{3}{*}{ Soybean } & Poisson's ratio & 0.4 \\
& Shear modulus $/ \mathrm{Pa}$ & $1.1 \times 10^{7}$ \\
& Density $/ \mathrm{kg} \cdot \mathrm{m}^{-3}$ & 1053 \\
\hline \multirow{2}{*}{ Cast iron } & Poisson's ratio & 0.3 \\
& Shear modulus $/ \mathrm{Pa}$ & $7 \times 10^{10}$ \\
& Density $/ \mathrm{kg} \cdot \mathrm{m}^{-3}$ & 7800 \\
\hline \multirow{2}{*}{$\begin{array}{c}\text { Soybean- } \\
\text { soybean }\end{array}$} & Collision recovery coefficient & 0.6 \\
& Static friction coefficient & 0.5 \\
& Rolling friction coefficient & 0.01 \\
\hline \multirow{2}{*}{$\begin{array}{c}\text { Soybean- } \\
\text { cast iron }\end{array}$} & Collision recovery coefficient & 0.6 \\
& Static friction coefficient & 0.3 \\
& Rolling friction coefficient & 0.01 \\
\hline
\end{tabular}

The soybeans used in this study were Jiyu202, which was widely planted in Northeast China, the major soybean production region of China. The physical properties of Jiyu202 are shown in Table 2.

The soybean seeds were modeled on EDEM. The seed model was composed of one spherical particle with diameter of $5.8 \mathrm{~mm}$ and four spherical particles with diameter of $4 \mathrm{~mm}$ (Figure 6). The model was $7.2 \mathrm{~mm}$ long, $6.8 \mathrm{~mm}$ wide and $5.8 \mathrm{~mm}$ thick. Simulation time was $10 \mathrm{~s}$ and the simulation process is shown in Figure 7.

In the first part of simulation test, the angle of agitating plates was set as the test factor. Here three types of agitating plates were designed (Figure 5). In the first part test, the seed filling velocity 
was considered as the indicator of agitating plate performance. A faster seed filling velocity indicates higher agitating plate performance.

In the second part of simulation test, with the position and number of agitating plates, and the radius of convex spoons as the factors, full tests were conducted, and the values of the factors are listed in Table 3.

Table 2 Physical properties of soybean seeds

\begin{tabular}{lcc}
\hline \multicolumn{1}{c}{ Physical property } & Mean & Standard error \\
\hline Length $L / \mathrm{mm}$ & 7.21 & 0.32 \\
Width $W / \mathrm{mm}$ & 6.75 & 0.32 \\
Thickness $T / \mathrm{mm}$ & 5.81 & 0.44 \\
Geometrical diameter $D / \mathrm{mm}$ & 6.52 & \\
Sphericity $\phi / \%$ & 92.35 & \\
Thousand seed mass/g & 180.55 & 0.21 \\
Angle of repose $\left./{ }^{\circ}\right)$ & 26.65 & 0.52 \\
Moisture content $/ \%$ & 13.24 & 0.36 \\
\hline
\end{tabular}

Note: Geometrical diameter calculated as $D=(L W T)^{1 / 3}$; Sphericity calculated as $\phi=\frac{(L W T)^{1 / 3}}{L} \times 100$.

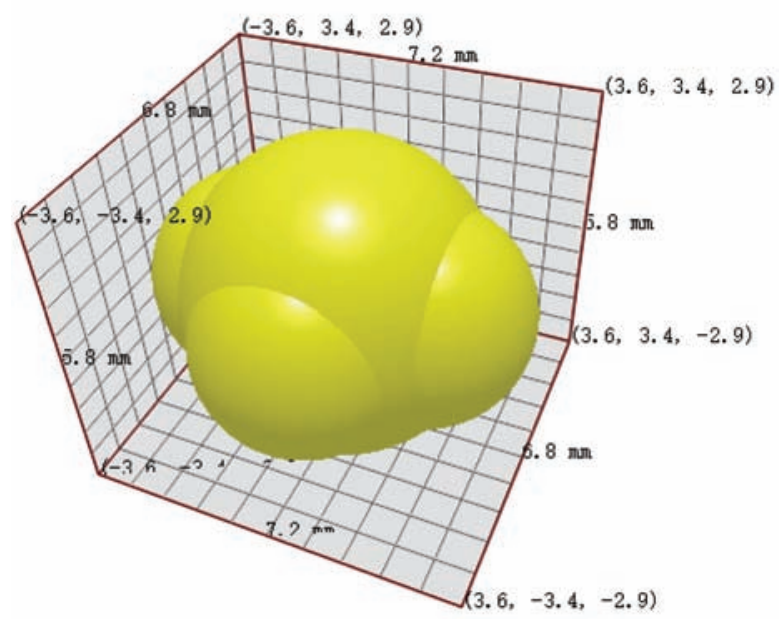

Figure 6 Schematic map of the seed model

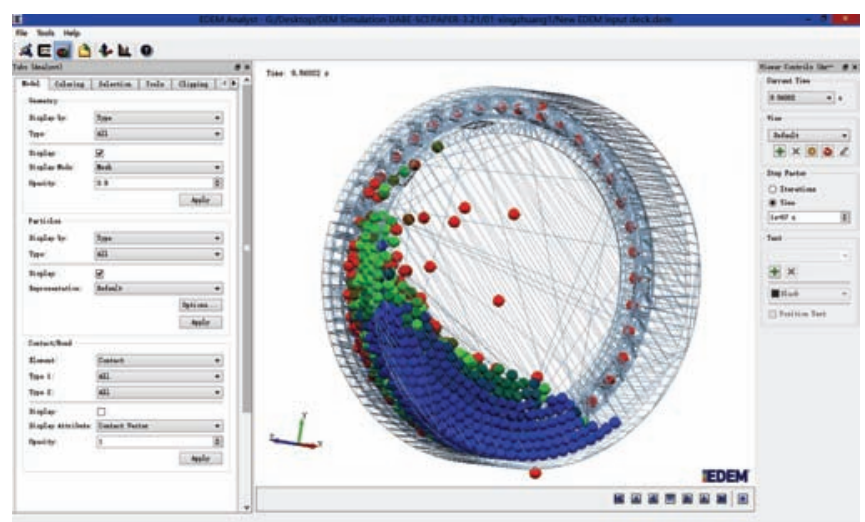

Figure 7 Schematic of seed metering device in simulation

Table 3 Levels of factors

\begin{tabular}{cccc}
\hline Level & $\begin{array}{c}\text { Diameter of convex } \\
\text { spoon: } A / \mathrm{mm}\end{array}$ & $\begin{array}{c}\text { Position of agitating } \\
\text { plate: } B / \mathrm{mm}\end{array}$ & $\begin{array}{c}\text { Number of agitating } \\
\text { plates: } C\end{array}$ \\
\hline 1 & 8 & 15 & 10 \\
2 & 12 & 25 & 15 \\
3 & 16 & 35 & 20 \\
\hline
\end{tabular}

Note: The position of an agitating plate was defined as the distance from the axial agitating plate to the margins of the horizontal seed filling disc as show in Figure 5 II.

\subsubsection{Indoor platform tests}

Indoor platform tests were performed on a JPS-12 seed metering device performance testing system ${ }^{[1,2,19,25]}$ with sticky belt in Laboratory of Agricultural Machinery, Jilin University (Figure 8). This system consisted of a seed metering device, convey belt, an industrial camera, an oil spray device, a computer, an electric control system and a frequency modulation motor. The seed metering device was motor-driven through the sprocket to rotate. The oil spray device sprayed the oil on the convey belts, forming an oil belt. When a seed injected from the seed metering device fell onto the oil belt, the seed only shifted very little, which reflected the seed metering performance of the seed metering device to the largest extent. The rotating speeds of the motors were controlled by the electric control system, while the rotating speed of the seed metering device and the linear speed of the convey belts were measured by sensors. During the tests, the seed metering device was fixed and the convey belts rotated. The backward movement of the convey belts was equivalent to the forward movement of the planter.

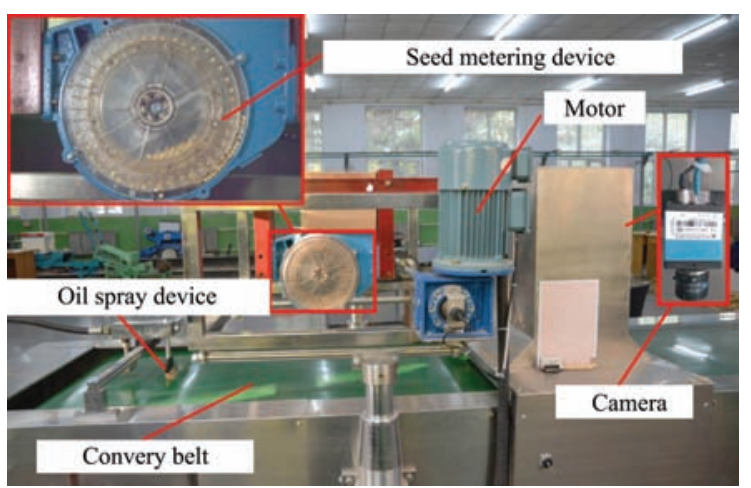

Figure 8 Platform experiment

Due to limitation of length of the convey belts, it was hard to measure a large amount of data, so the DMK 21AU04 industrial camera (resolution $=640 \times 480$, frequency $=60 \mathrm{fps}$ ) was used in data collection. The camera was mounted right above and aimed at the oil belt and recorded the seed distribution on the oil belt. The data were saved in the computer in the form of videos. In this way, the seed distributions were measured via videos and used to evaluate the performance of the seed metering device.

During the tests, motor 2 was first started, which drove the convey belts to move. Then the oil spray device and finally motor 2 were started, so the seed metering device began to rotate. One minute after the seed metering device was started, the camera started to record data and stopped after $2 \mathrm{~min}$. From the recorded data, 250 consecutive seeds were selected and statistically analyzed according to ISO, 1984 and GB/T 6973-2005. Each test was repeated five times.

Given that the seeds should be distributed on the oil belt by the specified seed spacing, it was estimated the rotating speed of the seed metering device and the linear speed of the convey belts should meet the following conditions:

$$
V_{2}=\frac{60 \cdot s \cdot m \cdot n}{1000}
$$

where, $V_{2}$ is the linear speed of the convey belts, $\mathrm{km} / \mathrm{h}$.

At $V_{2}=12 \mathrm{~km} / \mathrm{h}$, the rotation speed of the shaft was estimated by Equation (8) to be $50 \mathrm{r} / \mathrm{min}$.

\subsubsection{Indicators of seed metering performance}

Based on ISO7256/1-1984(E) Standard and GB/T6973-2005, multiple index, missing seeding index, qualified index and variable 
coefficient were selected as the indicators of seed metering performance.

Multiple index: $M U L=\frac{z_{1}}{Z} \times 100 \%$

where, $z_{1}$ is the number of seeds with inter-seed spacing smaller than half of the theoretical value (which was $10 \mathrm{~cm}$, the widely-used theoretical seed spacing in soybean planting in Northeast China); $Z$ is the total number of seeds statistically involved.

Missing seeding index: $M I S=\frac{\mathrm{z}_{2}}{Z} \times 100 \%$

where, $z_{2}$ is the number of seeds with inter-seed spacing smaller than 1.5 times the theoretical value.

Qualified index: $Q F I=100-M U L-M I S$

Variable coefficient: $V A R=\frac{\sqrt{\frac{1}{Z} \sum_{i=1}^{N}\left(x_{i}-\bar{x}\right)}}{\bar{x}} \times 100 \%$

where, $x_{i}$ is the $n^{\text {th }}$ seeds spacing; $\bar{x}$ is the average seeds spacing, $\bar{x}=\frac{1}{N} \sum_{i=1}^{N} x_{i}$.

\section{Results and discussion}

\subsection{Agitating plate simulation tests}

\subsubsection{Results}

At the rotating speed of $50 \mathrm{r} / \mathrm{min}$, the four types of seed metering devices with different agitating plates were simulated (Figure 9).

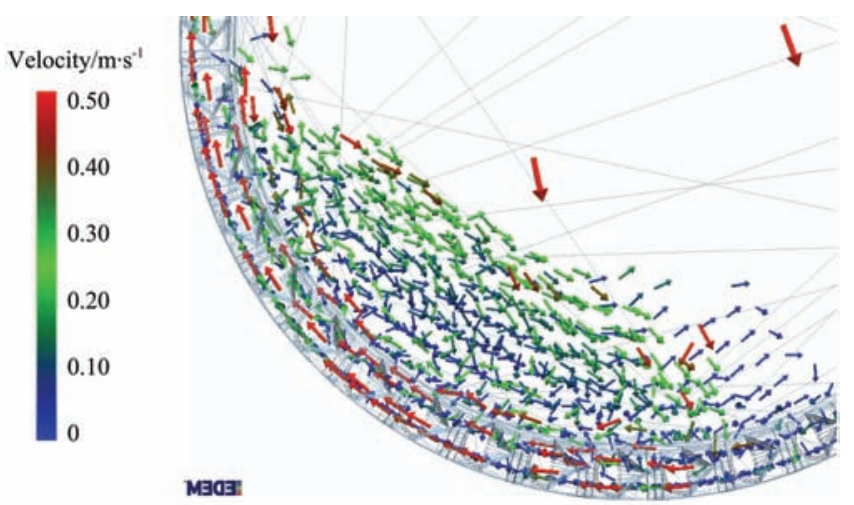

Without agitating plate

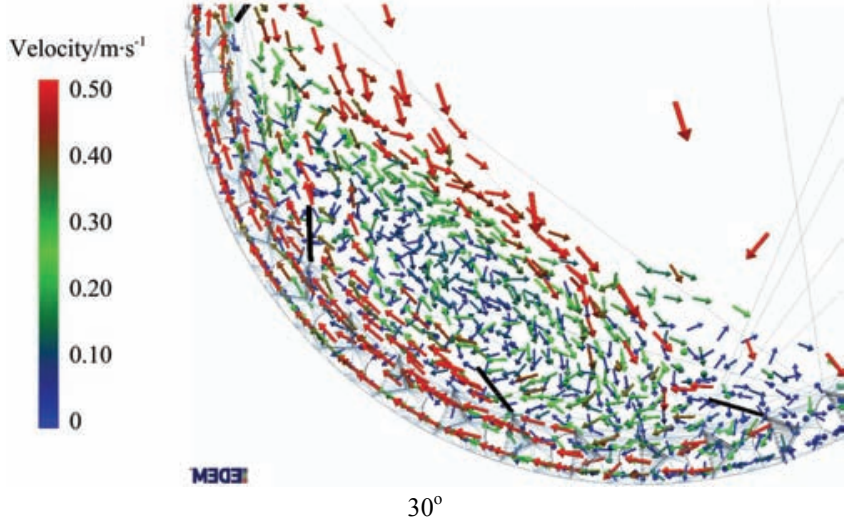

Figure 9 Four types of seed metering devices with different agitating plates

In EDEM, the seeds in the ascending zone were selected according to the mesh selection method as shown in Figure 10. The rotating speed of the horizontal seed filling disc was $50 \mathrm{r} / \mathrm{min}$, this disc contained 10 agitating plates, and the time interval between two adjacent agitating plates was $0.12 \mathrm{~s}$. Given the complete moving status of seeds after the agitating plates after passed the seeds, the statistical time was set at an interval of $0.04 \mathrm{~s}$, and the instantaneous speed and number of the seeds in the ascending zone were separately outputted.

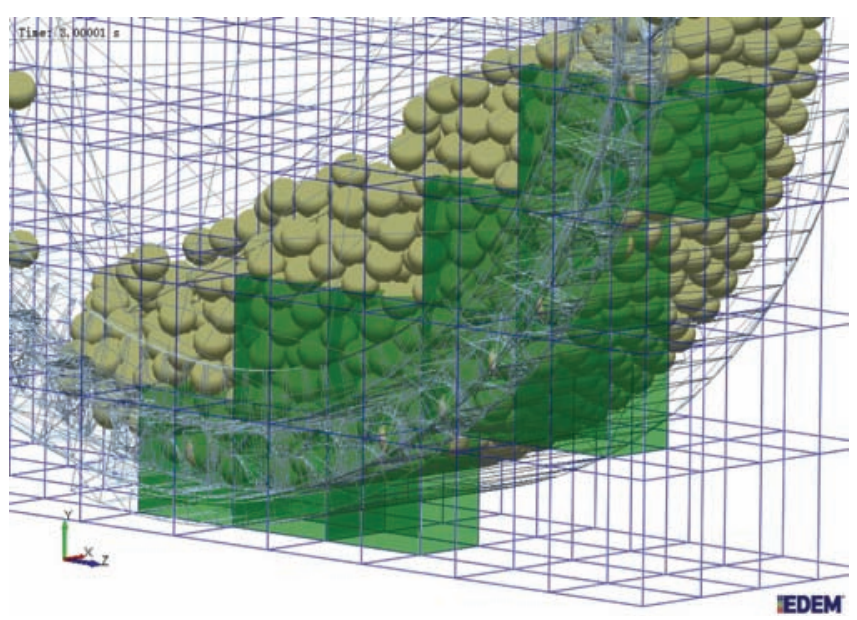

Figure 10 Selecting seeds

The intermediate parts of the simulation period were selected: $5.00 \mathrm{~s}, 5.04 \mathrm{~s}$ and $5.08 \mathrm{~s}$. The instantaneous speeds of the seeds in the ascending zone are shown in Figure 11. Clearly, the instantaneous speeds of seeds were significantly improved after the installation of agitating plates. The instantaneous speeds of agitating plates $30^{\circ}$ and $-30^{\circ}$ were both the largest at $5.00 \mathrm{~s}$, but not significantly different. At $5.04 \mathrm{~s}$, the instantaneous speeds of agitating plates $0^{\circ}$ and $30^{\circ}$ were not significantly different, but were significantly different from agitating plate $-30^{\circ}$. At $5.08 \mathrm{~s}$, the instantaneous speeds of three agitating plates were not significantly different.

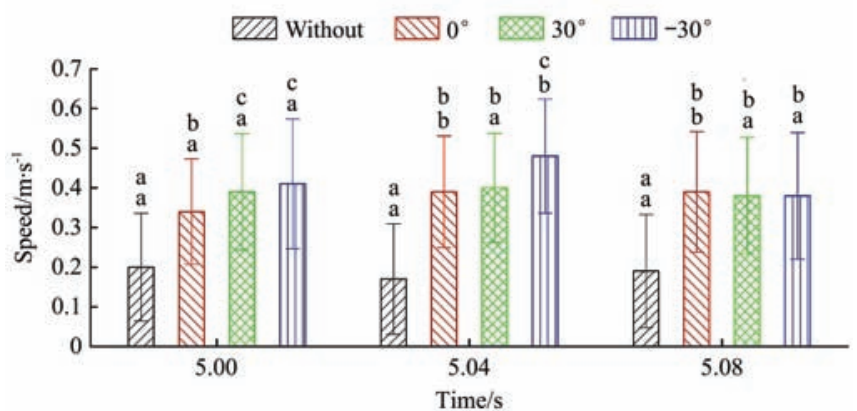

Note: At the same time point, the upper lowercases indicate the speeds were significantly different $(p<0.05)$ influence by the agitating plates. Moreover, the lowercases represent the variance of four agitating plates at three time points. With the same type of agitating plate, the under lowercases indicate the speeds were significantly different $(p<0.05)$ influence by time.

Figure 11 Effects of agitating plate and time on seed speed

With the absence of agitating plates, the instantaneous seed speeds did not change significantly with time. With the presence of agitating plate $0^{\circ}$, the instantaneous speeds of seeds at $5.04 \mathrm{~s}$ and $5.08 \mathrm{~s}$ were significantly larger than that at $5.00 \mathrm{~s}$. With agitating plate $30^{\circ}$, the instantaneous speed did not change significantly with time. With agitating plate $-30^{\circ}$, the instantaneous speed at $5.04 \mathrm{~s}$ was significantly larger than that at other time points. Thus, the instantaneous speed of agitating plate $30^{\circ}$ was more stable than agitating plate $0^{\circ}$ or $-30^{\circ}$.

The simulation time was selected to be the stable period (from $2 \mathrm{~s}$ to $8 \mathrm{~s}$ ). The number of seeds in the ascending zone was summarized every $0.04 \mathrm{~s}$. The number of seeds with the use of a 
specific agitating plate is shown in Figure 12. With the absence of agitating plate, the number of seeds in the ascending zone was maximized (mean $=110.6)$. After the addition of agitating plates, the number of seeds decreased to different degrees and fluctuated very severely. With the use of agitating plate $0^{\circ}, 30^{\circ}$ and $-30^{\circ}$, the average number of seeds was 104.8, 106.1 and 90.7, respectively. The results of analysis of variance are shown in Table 4. There agitating plates significantly affected the number of seeds. The number of seeds fluctuated most significantly with the use of agitating plate $-30^{\circ}$. The numbers of seeds were similar between agitating plates $0^{\circ}$ and $30^{\circ}$.

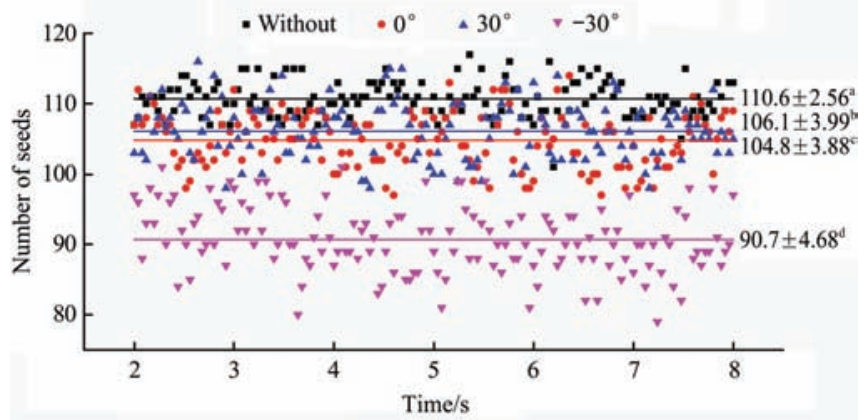

Note: Data are expressed as mean \pm standard deviation. The lowercases indicate significant difference at $p<0.05$ (the same below).

Figure 12 Number of seeds

Table 4 Results of DEM tests

\begin{tabular}{|c|c|c|c|c|c|}
\hline$A$ & $B$ & $C$ & $Q U I / \%$ & $M U L / \%$ & $M I S / \%$ \\
\hline \multirow{9}{*}{8} & \multirow{3}{*}{15} & 5 & $92.0 \pm 0.5$ & $3.3 \pm 0.5$ & $4.7 \pm 0.7$ \\
\hline & & 15 & $92.3 \pm 0.7$ & $4.1 \pm 0.5$ & $3.6 \pm 0.5$ \\
\hline & & 25 & $91.8 \pm 0.4$ & $2.7 \pm 0.3$ & $5.5 \pm 0.3$ \\
\hline & \multirow{3}{*}{25} & 5 & $91.7 \pm 0.5$ & $2.4 \pm 0.6$ & $5.9 \pm 0.5$ \\
\hline & & 15 & $91.6 \pm 0.9$ & $3.1 \pm 0.3$ & $5.3 \pm 0.7$ \\
\hline & & 25 & $91.5 \pm 0.5$ & $1.4 \pm 0.2$ & $7.1 \pm 0.7$ \\
\hline & \multirow{3}{*}{35} & 5 & $91.4 \pm 0.5$ & $1.1 \pm 0.3$ & $7.5 \pm 0.3$ \\
\hline & & 15 & $91.7 \pm 0.5$ & $1.6 \pm 0.6$ & $6.7 \pm 0.5$ \\
\hline & & 25 & $91.1 \pm 0.7$ & $0.3 \pm 0.3$ & $8.6 \pm 0.5$ \\
\hline \multirow{9}{*}{12} & \multirow{3}{*}{15} & 5 & $92.8 \pm 0.4$ & $5.5 \pm 0.5$ & $1.7 \pm 0.6$ \\
\hline & & 15 & $92.2 \pm 0.5$ & $6.3 \pm 0.8$ & $1.5 \pm 0.3$ \\
\hline & & 25 & $92.4 \pm 0.4$ & $4.8 \pm 0.6$ & $2.8 \pm 0.6$ \\
\hline & \multirow{3}{*}{25} & 5 & $93.4 \pm 0.7$ & $4.1 \pm 0.4$ & $2.5 \pm 0.5$ \\
\hline & & 15 & $93.6 \pm 0.6$ & $4.5 \pm 0.5$ & $1.9 \pm 0.7$ \\
\hline & & 25 & $93.0 \pm 0.6$ & $3.7 \pm 0.5$ & $3.3 \pm 0.9$ \\
\hline & \multirow{3}{*}{35} & 5 & $92.3 \pm 0.3$ & $3.8 \pm 0.5$ & $3.9 \pm 0.3$ \\
\hline & & 15 & $92.5 \pm 0.6$ & $4.1 \pm 0.5$ & $3.4 \pm 0.8$ \\
\hline & & 25 & $91.8 \pm 0.5$ & $3.1 \pm 0.3$ & $5.1 \pm 0.5$ \\
\hline \multirow{9}{*}{16} & \multirow{3}{*}{15} & 5 & $89.0 \pm 0.6$ & $10.5 \pm 0.5$ & $0.5 \pm 0.5$ \\
\hline & & 15 & $87.8 \pm 0.5$ & $11.9 \pm 0.5$ & $0.3 \pm 0.2$ \\
\hline & & 25 & $89.4 \pm 0.5$ & $9.7 \pm 0.8$ & $0.9 \pm 0.3$ \\
\hline & \multirow{3}{*}{25} & 5 & $89.9 \pm 0.7$ & $9.3 \pm 0.5$ & $0.8 \pm 0.6$ \\
\hline & & 15 & $88.9 \pm 0.5$ & $10.6 \pm 0.5$ & $0.5 \pm 0.3$ \\
\hline & & 25 & $89.7 \pm 0.5$ & $8.9 \pm 0.6$ & $1.4 \pm 0.6$ \\
\hline & \multirow{3}{*}{35} & 5 & $90.3 \pm 0.7$ & $7.9 \pm 0.6$ & $1.8 \pm 0.6$ \\
\hline & & 15 & $90.5 \pm 0.6$ & $8.2 \pm 0.6$ & $1.3 \pm 0.7$ \\
\hline & & 25 & $90.4 \pm 0.7$ & $7.5 \pm 0.3$ & $2.1 \pm 0.6$ \\
\hline
\end{tabular}

\subsubsection{Discussion}

The above test results clearly show the following conclusions. First, the instantaneous seed speed was significantly accelerated after installation of an agitating plate, indicating the agitating plate structure could significantly accelerate population migration via the impression on the population. It was proved the traditional mechanical seed metering devices were slow because the seed filling force of the driven seeds towards the seed collection institution was too slow. As a result, the seed filling force could be enlarged by adding more agitating plates, and thereby the seed filling speed of the mechanical seed metering devices could be quickened. Second, the installation angle of agitating plates would alter the population migration rules, such as at different instantaneous speeds and different population numbers in the ascending zone. These phenomena occurred because different installation angles would change the force directions of agitating plates imposed on the populations and thereby affect the migrating speeds at different directions. Therefore, agitating plate angle should guarantee that the instantaneous speed of the seeds in the ascending zone was large and stable, and that the number of seeds in the ascending zone was large and less fluctuating.

The agitating plate should guarantee that the instantaneous speeds of the seeds in the ascending zone was large and stable, and that the number of seeds in the ascending zone was large and less fluctuating. As for the instantaneous speed, it was maximized with the addition of agitating plate $-30^{\circ}$, but the instantaneous speeds were less stable. The instantaneous speeds of seeds with addition of agitating plates $30^{\circ}$ and $-30^{\circ}$ were not significantly different at either $5.00 \mathrm{~s}$ or $5.08 \mathrm{~s}$, and the speeds were stable with agitating plates $30^{\circ}$. The number of seeds was maximized with the addition of agitating plate $30^{\circ}$ and fluctuated similarly to the case of agitating plate $0^{\circ}$. With full consideration into the speed and number of seeds, the agitating plate $30^{\circ}$ was selected in the subsequent tests.

\subsection{Multifactor simulations tests}

\subsubsection{Results}

The three-factor simulation tests involving convex spoon diameter, positions of agitating plates, and number of agitating plates are illustrated in Table 4.

The results were summarized. The effects of position and number on the seed metering performance are illustrated in Figure 13 when diameter is unchanged.

\subsubsection{Effects on qualified index}

The effects of different factors on the qualified index are illustrated in Figure 14. The qualified index was significantly affected by convex spoon diameter, agitating plate position and number.

The qualified indices with convex spoon diameters of 8,12 and $16 \mathrm{~mm}$ are significantly different. With the rise of diameter, the qualified index first rises, maximizes and minimizes at the diameter of 12 and $16 \mathrm{~mm}$, respectively, and then declines.

At the diameter of $8 \mathrm{~mm}$, the agitating plate position significantly affects the qualified index. With the increase of agitating plate position, the qualified index gradually declines and maximizes at the position of $15 \mathrm{~mm}$. The qualified index is not significantly affected by the number of agitating plates, and does not significantly change with the increase of agitating plate number. At the agitating plate position of $15 \mathrm{~mm}$, the qualified index maximizes to $92.3 \%$ when the agitating plate number is 15 .

At the diameter of $12 \mathrm{~mm}$, the agitating plate position significantly affects the qualified index. With the increase of agitating plate position, the qualified index first rises, then declines, and maximizes at the position of $25 \mathrm{~mm}$. The qualified rate is not significantly affected by the number of agitating plates, and does not significantly change with the increase of agitating plate number. 
At the agitating plate position of $25 \mathrm{~mm}$, the qualified index maximizes to $93.6 \%$ when the number of agitating plates is 15 .

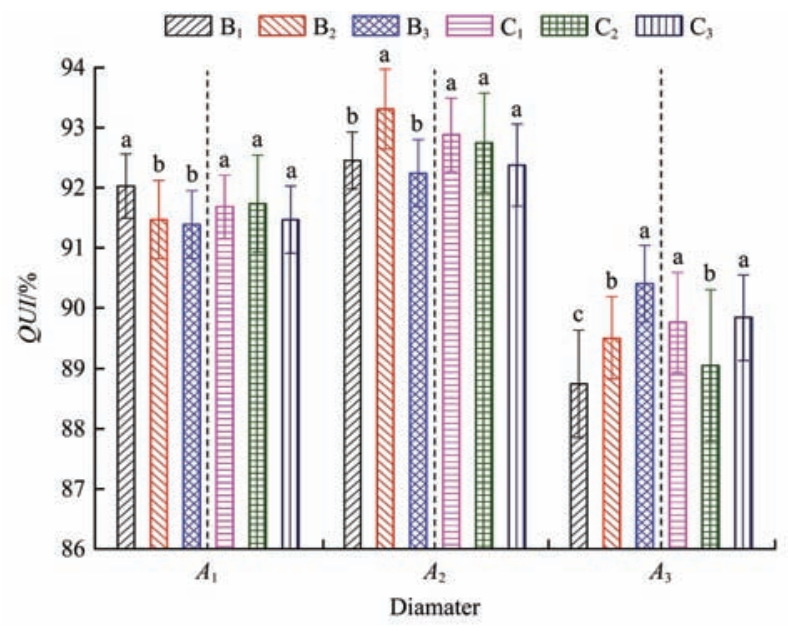

a. Effects on qualified index

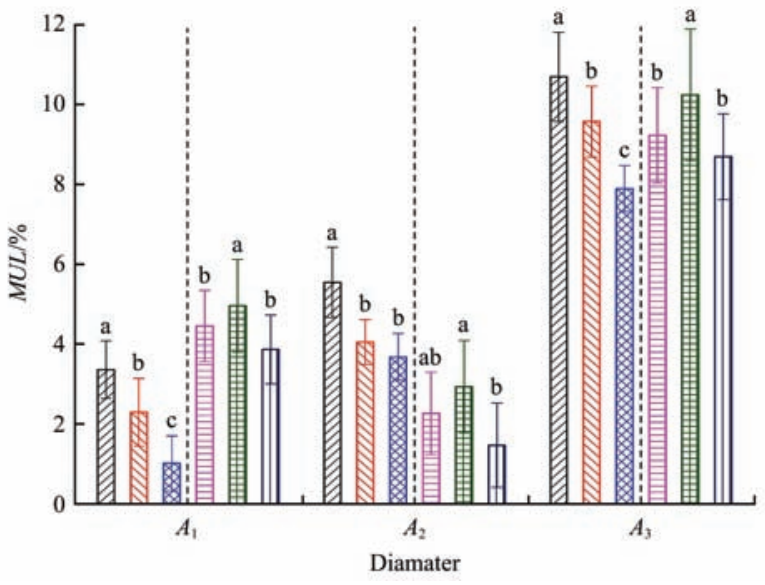

b. Effects on multiple index

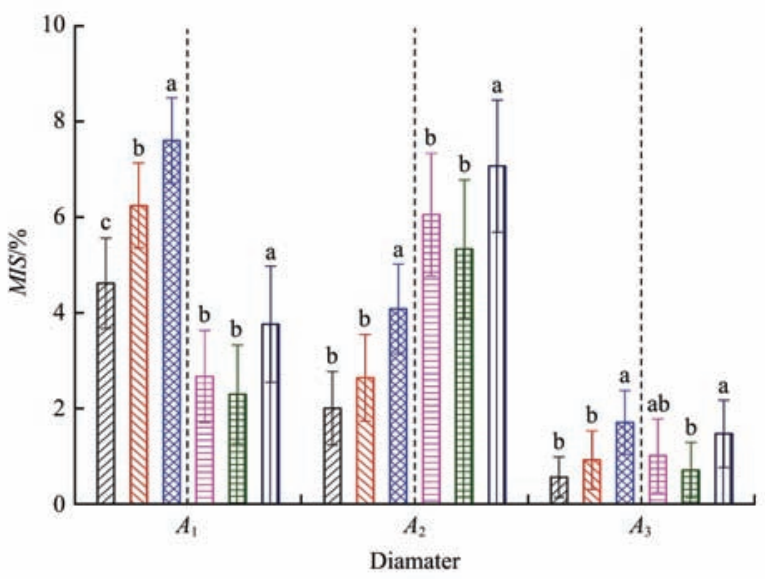

c. Effects on missing seeding index

Figure 13 Effects of positions and number of agitating plates on performance indices under different diameter

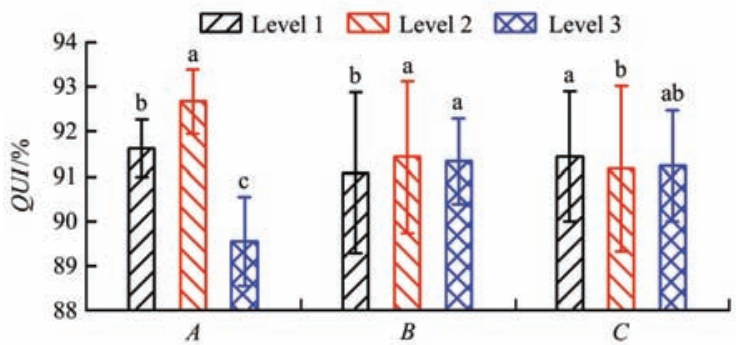

Figure 14 Effects of different factors on qualified index
At the diameter of $16 \mathrm{~mm}$, the agitating plate position significantly affects the qualified index. With the increase of agitating plate position, the qualified index gradually declines and maximizes at the position of $35 \mathrm{~mm}$. The qualified index is significantly affected by the number of agitating plates. With the increase of agitating plate number, the qualified index first drops and then rises. The qualified indices with the agitating plate numbers of 5 and 25 are very large, but not significantly different. At the agitating plate position of $35 \mathrm{~mm}$, the qualified index maximizes to $90.5 \%$ when the number of agitating plates is 25 .

3.2.3 Effects on multiple index

The effects of different factors on the multiple index are illustrated in Figure 15. The multiple index is significantly affected by convex spoon diameter, agitating plate position and number.

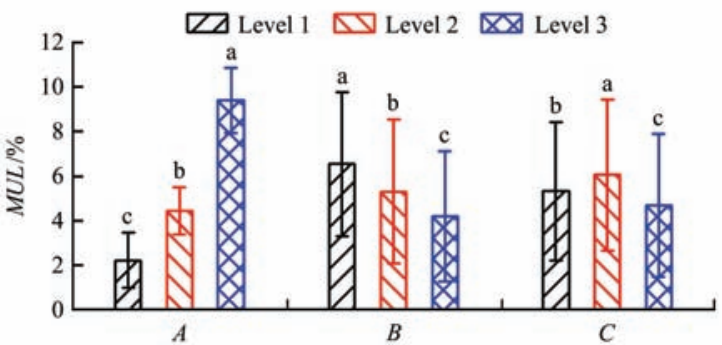

Figure 15 Effects of different factors on multiple index

The multiple indices with convex spoon diameters of 8,12 and $16 \mathrm{~mm}$ are significantly different. With the rise of spoon diameter, the multiple index first rises, then declines and maximizes and minimizes at diameter of 12 and $16 \mathrm{~mm}$, respectively.

At the diameter of $8 \mathrm{~mm}$, the agitating plate position significantly affects the multiple index. With the increase of agitating plate position, the multiple index gradually declines and maximizes at the position of $15 \mathrm{~mm}$. The multiple index is significantly affected by the number of agitating plates. With the increase of agitating plate number, the multiple index first rises and then drops. The multiple index maximizes when the number of agitating plates is 15 . At the agitating plate position of $15 \mathrm{~mm}$, the multiple index maximizes to $4.1 \%$ when the number of agitating plates is 15 . At the agitating plate position of $35 \mathrm{~mm}$, the multiple index minimizes to $0.3 \%$ when the number of agitating plates is 25 .

At the diameter of $12 \mathrm{~mm}$, the agitating plate position significantly affects the multiple index. With the increase of agitating plate position, the multiple index gradually declines and maximizes at the position of $15 \mathrm{~mm}$. The multiple index is significantly affected by the number of agitating plates. With the increase of agitating plate number, the multiple index first rises and then drops. The multiple index maximizes when the number of agitating plates is 15 . At the agitating plate position of $15 \mathrm{~mm}$, the multiple index maximizes to $6.3 \%$ when the number of agitating plates is 15 . At the agitating plate position of $35 \mathrm{~mm}$, the multiple index maximizes to $3.1 \%$ when the number of agitating plates is 25 .

At the diameter of $16 \mathrm{~mm}$, the agitating plate position significantly affects the multiple index. With the increase of agitating plate position, the multiple index gradually declines, and maximizes at the position of $15 \mathrm{~mm}$. The multiple index is significantly affected by the number of agitating plates. With the increase of agitating plate number, the multiple index first rises and then drops. The multiple index maximizes when the number of agitating plates is 15 . At the agitating plate position of $15 \mathrm{~mm}$, 
the multiple index maximizes to $11.9 \%$ when the number of agitating plates is 15 . At the agitating plate position of $35 \mathrm{~mm}$, the multiple index minimizes to $7.5 \%$ when the number of agitating plates is 25 .

3.2.4 Effects on missing seeding index

The effects of different factors on the missing seeding index are illustrated in Figure 16. The missing seeding index is significantly affected by convex spoon diameter, agitating plate position and number.

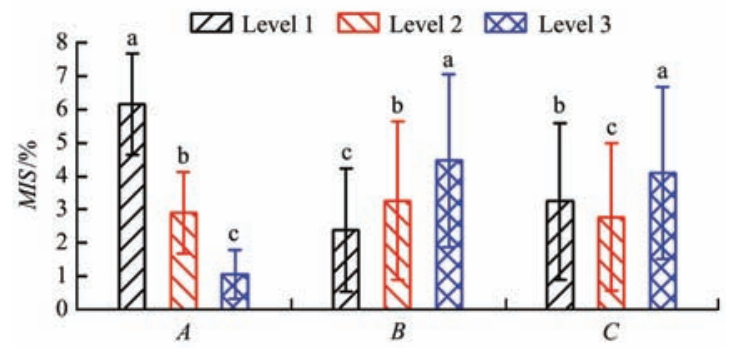

Figure 16 Effects of different factors on missing seeding index

The missing seeding indices with convex spoon diameters of 8 , 12 and $16 \mathrm{~mm}$ are significantly different. With the increase of diameter, the missing seeding index gradually declines and maximizes and minimizes at the diameter of 8 and $16 \mathrm{~mm}$, respectively.

At the diameter of $8 \mathrm{~mm}$, the agitating plate position significantly affects the missing seeding index. With the increase of agitating plate position, the missing seeding index gradually rises, and maximizes and minimizes at the position of 35 and $15 \mathrm{~mm}$, respectively. The missing seeding index is significantly affected by the number of agitating plates. With the increase of agitating plate number, the missing seeding index first drops and then rises. The missing seeding index maximizes and minimizes when the numbers of agitating plates are 25 and 15, respectively. At the agitating plate position of $35 \mathrm{~mm}$, the missing seeding index maximizes to $8.6 \%$ when the number of agitating plates is 25 . At the agitating plate position of $15 \mathrm{~mm}$, the missed seeding rate minimizes to $3.6 \%$ when the number of agitating plates is 15 .

At the diameter of $12 \mathrm{~mm}$, the agitating plate position significantly affects the missing seeding index. With the increase of agitating plate position, the missing seeding index gradually rises, and maximizes and minimizes when the positions of agitating plates are 35 and $15 \mathrm{~mm}$, respectively. The missing seeding index is significantly affected by the number of agitating plates. With the increase of agitating plate number, the missing seeding index first drops and then rises. The missing seeding index maximizes and minimizes when the numbers of agitating plates are 25 and 15 , respectively. At the agitating plate position of $35 \mathrm{~mm}$, the missed seeding maximizes to $5.1 \%$ when the number of agitating plates is 25. At the agitating plate position of $15 \mathrm{~mm}$, the missed seeding rate minimizes to $1.5 \%$ when the number of agitating plates is 15 .

At the diameter of $16 \mathrm{~mm}$, the agitating plate position significantly affects the missing seeding index. With the increase of agitating plate position, the missing seeding index gradually rises, and maximizes and minimizes at the position of 35 and 15 $\mathrm{mm}$, respectively. The missing seeding index is significantly affected by the number of agitating plates. With the increase of agitating plate number, the missing seeding index first drops and then rises. The missing seeding index maximizes and minimizes when the numbers of agitating plates are 25 and 15, respectively. At the agitating plate position of $35 \mathrm{~mm}$, the missing seeding index maximizes to $2.1 \%$ when the number of agitating plates is 25 . At the agitating plate position of $15 \mathrm{~mm}$, the missing seeding index minimizes to $0.3 \%$ when the number of agitating plates is 15 .

\subsubsection{Regression analysis}

With the convex spoon diameter, agitating plate position and agitating plate number as the factors, then the effects of each factor and their interaction on the qualified index, multiple index and missing seeding index by using analysis of variance were computed (Table 5). The convex spoon diameter and agitating plate position both significantly affected the qualified index, and these two factors interacted. But the agitating plate number did not significantly affect the qualified index. The convex spoon diameter, agitating plate position and agitating plate number all significantly affected the multiple index, but the three factors did not interact with each other. The convex spoon diameter, agitating plate position and agitating plate number all significantly affect the missing seeding index, and the first two factors interacted.

Table 5 Significance analysis of different factors on performance indices

\begin{tabular}{cccc}
\hline \multirow{2}{*}{ Factors } & \multicolumn{3}{c}{ Performance indices } \\
\cline { 2 - 4 } & QUI & MUL & $M I S$ \\
\hline$A$ & $<0.001^{* * *}$ & $<0.001^{* * *}$ & $<0.001^{* * *}$ \\
$B$ & 0.515 & $<0.001^{* * *}$ & $<0.001^{* * *}$ \\
$C$ & 0.403 & $0.0331^{*}$ & $0.002^{* *}$ \\
$A^{2}$ & $<0.001^{* * *}$ & $<0.001^{* * *}$ & $0.001^{* *}$ \\
$B^{2}$ & $0.027^{*}$ & 0.079 & 0.057 \\
$C^{2}$ & 0.056 & 0.016 & $<0.001^{* * *}$ \\
$A^{*} B$ & $0.015^{*}$ & 0.153 & $0.009^{* *}$ \\
$A^{*} C$ & 1.000 & 0.449 & 0.341 \\
$B^{*} C$ & 0.926 & 1.000 & 0.870 \\
\hline
\end{tabular}

Note: * Indicates significance at $p \leq 0.05, * *$ Indicates significance at $P \leq 0.01$, $* * *$ Indicates significance at $p \leq 0.001$.

The three performance indices were fitted by regression equations according to the analysis of variance in Table 5. After the factors with insignificant effects were ignored, the regression equation involved the significant factors:

$Y_{1}=76.96+2.73 A+0.13 B+0.02 A B-0.15 A^{2}-(7.30 E-3) \cdot B^{2}$

where, $Y_{1}$ is the qualified index, and the modeling coefficient of determination was $R^{2}=0.9602, F=25.51 \quad(p<0.001)$, indicating the regression equation was highly reliable and could accurately predict the changes of qualified index.

$$
Y_{2}=10.49-1.49 A-0.12 B+0.13 C+0.10 A^{2}-(5.55 E-3) \cdot C^{2}
$$

where, $Y_{2}$ is the multiple index, and the modeling coefficient of determination was $R^{2}=0.9844, F=139.09(p<0.001)$, indicating the regression equation was highly reliable and could accurately predict the changes of multiple index.

$$
Y_{3}=11.49-1.43 A+0.27 B-0.30 C-0.01 A B+0.05 A^{2}+0.01 C^{2}
$$

where, $Y_{3}$ is the missing seeding index, and the modeling coefficient of determination was $R^{2}=0.9837, F=100.41(P<0.001)$, indicating the regression equation was highly reliable and could accurately predict the changes of missing seeding index.

According to the test results and regression equations, the optimal parameter combination under the lowest missing seeding index and highest qualified index on MATLAB was determined. The combination was: convex spoon diameter $=11.0 \mathrm{~mm}$; agitating plate position $=24.4 \mathrm{~mm}$; number of agitating plates $=12.7$. The 
corresponding results were: qualified index of simulation tests $=$ $93.9 \%$; multiple index $=3.9 \%$; missing seeding index rate $=2.2 \%$.

\subsubsection{Discussion}

The above results show that first, the convex spoon diameter significantly affected seed spacing qualified rate, multiple index, and missing seeding index. This was because the convex spoon diameter decided the limit time of the seed collecting device in finishing seed collection. When the seed collection time of the seed collecting device was shorter than the limit time, or namely the seed filling practice was successfully finished, while the seed collection time was affected by the population migration speed. Thus, when the population motion speed was unchanged, increasing the convex spoon radius could enlarge the limit time of practice and thereby reduce the occurrence of leakage. However, a further increase of convex spoon radius would raise the probability to collect multiple seeds, thereby increasing the multiple index. Thus, the qualified rate of sowing would first increase and then decrease with the rise of convex spoon diameter. It is indicated the convex spoon diameter and seed spacing qualified rate are related following certain rules. In this study, regression equations were identified through regression analysis, and thereby, the optimal convex spoon diameter was $11 \mathrm{~mm}$. Secondly, the positions of agitating plates significantly affected seed spacing qualified rate, multiple index, and missing seeding index. Thus, the seeds during seed filling practices were affected by self-gravity, the exerted force of the agitating plate, and the inner force of the population. The joint action of the three forces drove the seeds to move to the seed collecting device. The seed closest to the seed collecting device was the first to enter the collecting device, so the seed filling was finished. The seeds at different positions were affected by the agitating plates as the force was influenced by the distance between the agitating plate and the seed. A larger distance indicated the force from the agitating plate was smaller, which decelerated the seed filling speed and increased the missing seeding index. Meanwhile, the multiple index increased with the decline of the distance. When the convex spoon diameter was large $(16 \mathrm{~mm})$, the limit time of seed collection was large. At this moment, a larger seed filling speed would easily cause large-area repeated seeding. Thus, when the convex spoon diameter was large $(16 \mathrm{~mm})$, the qualified rate of seed spacing would increase with the rise of agitating plate position. When the convex spoon diameter was small $(8 \mathrm{~mm})$, the qualified rate of seed spacing declined with the rise of agitating plate position, indicating that the agitating plate position was related with the seed spacing qualified rate following certain rules and that the convex spoon diameter interacted with the agitating plate position. Thirdly, the number of agitating plates significantly affected the multiple index and missed seeding rate. However, the effect on seed spacing qualified rate was insignificant when the convex spoon radius was small ( 8 or $12 \mathrm{~mm}$ ), indicating when the number of agitating plates was large, the seed filling ability imposed by the population was enhanced. However, when the agitating plates were inside the population, the too large number of agitating plates would interfere with the population motion paths and thereby decelerated the population motion. This result indicates the number of agitating plates and the qualified rate of seed spacing are correlated numerically. In conclusion, after the regression of test results, we identified the regression equations underlying the relationships of convex spoon diameter, number of agitating plates, or positions of agitating plates with the seed metering performance indices. Thereby, the regression equations were optimized, and the optimal design parameter combination was identified.

\subsection{Platform tests}

\subsubsection{Results}

The optimal result was identified through regression analysis, under the conditions of convex spoon diameter $=11 \mathrm{~mm}$, agitating plate position $=24.4 \mathrm{~mm}$, number of agitating plates $=13$, and a physical prototype of seed metering devices was manufactured. The indoor platform tests involving a traditional shaped-hole seed metering device, a suction seed metering device and our new seed metering device were conducted at the working speeds of $6,8,10$ and $12 \mathrm{~km} / \mathrm{h}$ (Figure 17). The shaped-hole seed metering device was a vertical-disc shaped-hole seed metering device (Kinze, US). A suction seed metering device (Maschio, Italy) with negative pressure of $4 \mathrm{kPa}$ was used.

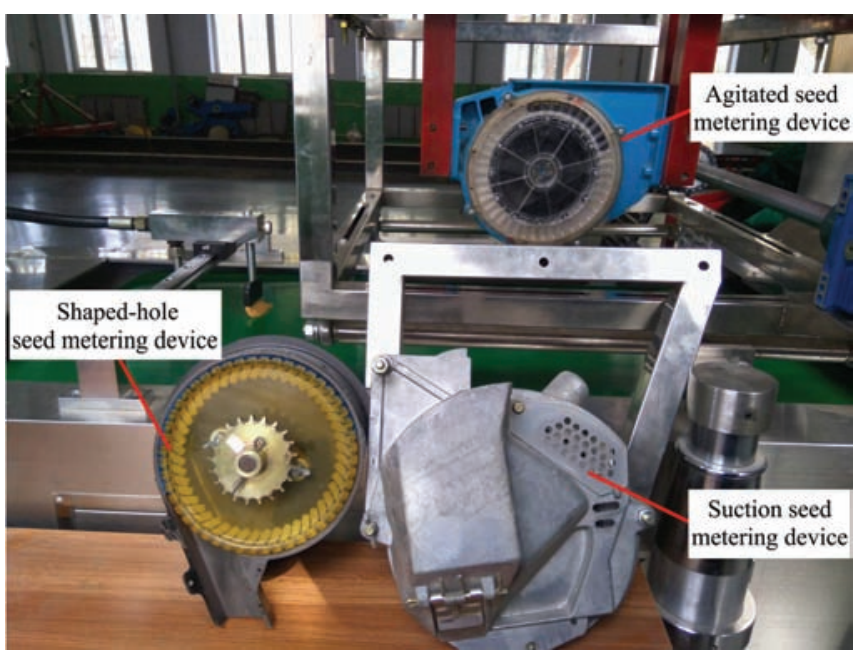

Figure 17 Platform tests of three seed metering devices

The qualified indices, multiple indices, missing seeding indices and variable coefficient from platform tests of the three seed metering devices are shown in Table 6 , the qualified indices and missing seeding indices are shown in Figure 18. With the rise of advancing speed, the qualified indices of the three seed metering devices all decrease. The qualified indices did not change severely at the advancing speed of $8-10 \mathrm{~km} / \mathrm{h}$, but decreased largely at the advancing speed below $8 \mathrm{~km} / \mathrm{h}$ and above $10 \mathrm{~km} / \mathrm{h}$, especially the shaped-hole device, while the agitated horizontal seed filling seed metering device and the pneumatic seed metering device were not significantly different.

Table 6 Results of platform tests

\begin{tabular}{cccccc}
\hline & Speed $/ \mathrm{km} \cdot \mathrm{h}^{-1}$ & $Q U I / \%$ & $M U L / \%$ & $M I S / \%$ & $V A R / \%$ \\
\hline Agitated seed & 6 & $91.6 \pm 0.6$ & $7.6 \pm 0.6$ & $0.8 \pm 0.3$ & $9.4 \pm 0.2$ \\
metering device & 10 & $95.0 \pm 0.6$ & $2.5 \pm 0.7$ & $2.5 \pm 0.5$ & $14.6 \pm 0.6$ \\
& 12 & $93.1 \pm 0.7$ & $2.1 \pm 0.4$ & $4.8 \pm 0.6$ & $19.1 \pm 0.4$ \\
\hline & 6 & $92.3 \pm 0.5$ & $7.2 \pm 0.9$ & $0.5 \pm 0.4$ & $10.8 \pm 0.5$ \\
Suction seed & 8 & $96.1 \pm 0.8$ & $2.4 \pm 0.5$ & $1.5 \pm 0.5$ & $15.7 \pm 0.4$ \\
metering device & 10 & $95.4 \pm 0.6$ & $1.2 \pm 0.4$ & $3.4 \pm 0.4$ & $19.7 \pm 0.2$ \\
& 12 & $93.7 \pm 0.6$ & $0.2 \pm 0.2$ & $6.1 \pm 0.6$ & $22.8 \pm 0.4$ \\
\hline & 6 & $86.9 \pm 0.9$ & $9.9 \pm 0.8$ & $3.2 \pm 0.4$ & $13.7 \pm 0.3$ \\
Shaped-hole seed & 8 & $91.2 \pm 0.6$ & $4.7 \pm 0.4$ & $4.1 \pm 0.5$ & $17.4 \pm 0.5$ \\
metering device & 10 & $88.9 \pm 0.8$ & $2.9 \pm 0.4$ & $8.2 \pm 0.7$ & $21.8 \pm 0.6$ \\
& 12 & $83.1 \pm 1.2$ & $1.4 \pm 0.7$ & $15.5 \pm 0.5$ & $26.4 \pm 0.3$ \\
\hline
\end{tabular}


With the rise of advancing speed, the missing seeding indices of the three seed metering devices all increased. The missing seeding index of the shaped-hole device was higher than the other two devices and increased most significantly. The missing seeding indices of the agitated device and the pneumatic device were not significantly different and both changed little at the speed of $6-10 \mathrm{~km} / \mathrm{h}$, but both increased largely at the speed of 10 $12 \mathrm{~km} / \mathrm{h}$

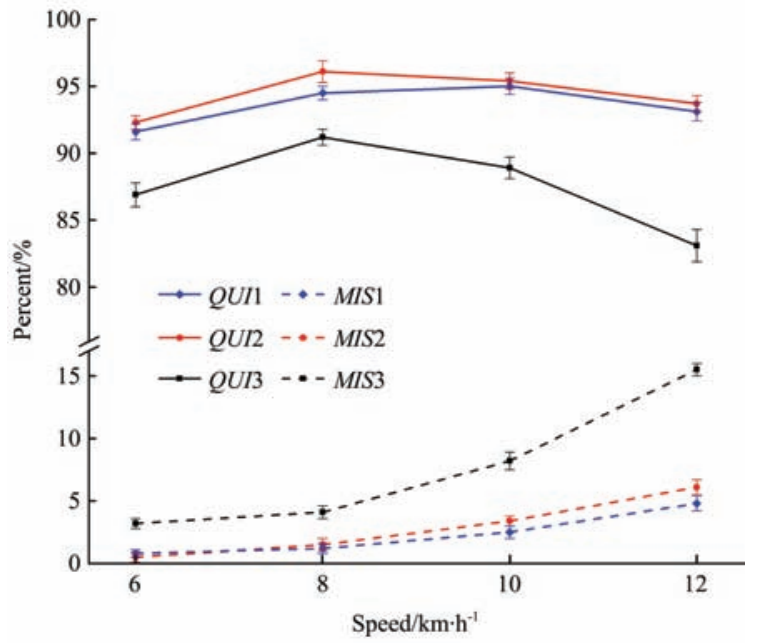

1. Agitated seed metering device 2. Suction seed metering device 3. Shapedhole seed metering device

Figure 18 Qualified indices and missing seeding indices of Platform tests

With the increase of speed, the seed spacing variation coefficients of all three types of seed metering devices rose. The seed spacing variation coefficient of traditional seed metering devices was significantly larger than the other two types and rose significantly. The seed spacing variation coefficient of agitated seed metering devices was insignificantly smaller than that of pneumatic seed metering devices. The seed spacing variation coefficients of the agitated seed metering devices at 6 and $12 \mathrm{~km} / \mathrm{h}$ were $9.4 \%$ and $19.1 \%$, respectively.

At the speed of $12 \mathrm{~km} / \mathrm{h}$, the agitated seed metering device had a qualified index of $93.1 \%$, multiple index of $2.1 \%$, missing seeding index of $4.8 \%$, and variable coefficient of $19.1 \%$.

The platform tests suggest that the new seed metering device significantly outperforms the mechanical seed metering device and has a similar effect as the pneumatic seed metering device, indicating the new device satisfies the requirements for precision soybean seeding.

\subsubsection{Discussion}

First, the agitated seed metering devices under high-speed seeding operation could reach the seeding quality of pneumatic seed metering devices and significantly outperformed the mechanical seed metering devices. These three types of seed metering devices were not significantly different under low-speed practices. These results indicate the agitating plates and horizontal seed filling of the agitated seed metering devices enhanced the seed filling force imposed on the seeds, accelerated the population motion and enlarged the limit time of seed filling operation, thereby improving the seed filling efficiency compared to that of pneumatic seed metering devices. The major reason why the mechanical seed metering devices were unfeasible to high-speed seeding practices was the too slow seed filling speed. Thus, an appropriate design of structure and parameters could accelerate the population migration and make mechanical seed metering devices feasible to high-speed seeding practices. Secondly, the seed spacing variation coefficient of agitated seed metering devices is smaller than that of pneumatic seed metering devices, which is mainly because the airflow transport is less stable than agitating plates. It is indicated the agitating plate outstands as its constant rotating speed imposes an influence on population motion.

\section{Conclusions}

1) An agitated seed metering device with horizontal seed filling, which was suitable for high-speed works and combined horizontal seed filling and agitated seed filling, was designed. The agitated seed filling could improve the seed filling acceleration, while the horizontal seed filling could increase the between-spoon space or namely the seed filling speed, thereby decreasing the missing seeding index without an increase of multiple index.

2) The angle of agitating plates significantly affected both seed moving speed and seed number. At the agitating plate angle of $-30^{\circ}$, the instantaneous speed of seeds maximized, but was not significantly different from that at the angle of $30^{\circ}$. The seed instantaneous speed at the agitating plate angle of $30^{\circ}$ was the most stable, with the largest seed number and least fluctuation of seed number. Thus, at the agitating plate angle of $30^{\circ}$, the agitated seed metering device with horizontal seed filling showed the best high-speed seeding performance.

3) The convex spoon diameter and agitating plate position both significantly affected the qualified index, and these two factors interacted. But the agitating plate number did not significantly affect the qualified index. The convex spoon diameter, agitating plate position and agitating plate number all significantly affected the multiple index, but the three factors did not interact. The convex spoon diameter, agitating plate position and agitating plate position number all significantly affected the missing seeding index, and the first two factors interacted with each other. Regression analysis showed that at the lowest missing seeding index and the highest qualified index, the agitated seed metering device performed the best under the optimal parameter combination: convex spoon diameter was $11.0 \mathrm{~mm}$, agitating plate position was $24.4 \mathrm{~mm}$ and number of agitating plates was 13 . Platform tests showed when the seeding speed was $12 \mathrm{~km} / \mathrm{h}$, the qualified index was $93.1 \%$, multiple index was $2.1 \%$, missing seeding index was $4.8 \%$ and variable coefficient was $19.1 \%$. The working efficiency was not significantly different from that of the pneumatic seed metering device, but was significantly higher than that of the mechanical seed metering device under high-speed practices.

\section{Acknowledgements}

We acknowledge that the research was financially supported by the 13th Five-Year Plan for National Science and Technology (Grant No. 2016YFD0700302); National Natural Science Foundation of China (51705194); (JJKH20170811KJ).

\section{[References]}

[1] Zhai J B, Xia J F, Zhou Y, Zhang S. Design and experimental study of the control system for precision seed-metering device. Int J Agric \& Biol Eng, 2014; 7(3): 13-18.

[2] Yang S, Zhang S M. Design and parameter optimization of flexible comb-type grass seed metering device. Int J Agric \& Biol Eng, 2015; 8(1) 9-16.

[3] Qi J T, Jia H L, Li Y, Yu H B, Liu X H, Lan Y B, et al. Design and test of fault monitoring system for corn precision planter. Int J Agric \& Biol Eng, 2015; 8(6): 13-19. 
[4] Rajaiah P, Mani I, Kumar A, Lande S D, Singh A K, Vergese C. Development and evaluation of electronically controlled precision seed-metering device for direct-seeded paddy planter. Indian Journal of Agricultural Sciences, 2016; 86(5): 598-604.

[5] Parish R L, McCoy J E, Bracy R P. Belt-type seeder for soybeans. Applied Engineering in Agriculture, 1999; 15(2): 103-106.

[6] Singh R C, Singh G, Saraswat D C. Design and operational parameters of a pneumatic seed metering device for planting of groundnut (Arachis hypogaea) seeds. Indian Journal of Agricultural Sciences, 2007; 77(1): 40-42.

[7] Staggenborg S A, Taylor R K, Maddux L D. Effect of planter speed and seed firmers on corn stand establishment. Applied Engineering in Agriculture, 2004; 20(5): 573-580.

[8] Karayel D, Ozmerzi A. Evaluation of three depth-control components on seed placement accuracy and emergence for a precision planter. Applied Engineering In Agriculture, 2008; 24(3): 271-276.

[9] Mao X, Yi S J, Tao G X, Yang L, Liu H Y, Ma Y C. Experimental study on seed-filling performance of maize bowl-tray precision seeder. Int $\mathrm{J}$ Agric \& Biol Eng, 2015; 8(2): 31-38.

[10] Yi S J, Liu Y F, Wang C, Tao G X, Liu H Y, Wang R H. Experimental study on the performance of bowl-tray rice precision seeder. Int J Agric \& Biol Eng, 2014; 7(1): 17-25.

[11] Panning J W, Kocher M F, Smith J A, Kachman S D. Laboratory and field testing of seed spacing uniformity for sugarbeet planters. Applied Engineering in Agriculture, 2000; 16(1): 7-13.

[12] Zhao Z, Wu Y F, Yin J J, Tang Z. Monitoring method of rice seeds mass in vibrating tray for vacuum-panel precision seeder. Computers And Electronics In Agriculture, 2015; 114: 25-31.

[13] St Jack D, Hesterman D C, Guzzomi A L. Precision metering of Santalum spicatum (Australian Sandalwood) seeds. Biosystems Engineering, 2013; 115(2): 171-183.

[14] Yang L, Yan B X, Cui T, Yu Y M, He X T, Liu Q W, et al. Global overview of research progress and development of precision maize planters. Int J Agric \& Biol Eng, 2016; 9(1): 9-26.

[15] Frabetti D R, Resende R C, Queiroz D M, Fernandes H C, Solza C M.
Development and evaluation performance of a punch planter for direct sowing of corn. Revista Brasileira De Engenharia Agricola E Ambiental, 2011; 15(2): 199-204.

[16] Karayel D, Wiesehoff M, Ozmerzi A, Muller J. Laboratory measurement of seed drill seed spacing and velocity of fall of seeds using high-speed camera system. Computers and Electronics in Agriculture, 2006; 50(2): 89-96.

[17] Wang J W, Tang H, Wang J F, Li X, Huang H N. Optimization design and experiment on ripple surface type pickup finger of precision maize seed metering device. Int J Agric \& Biol Eng, 2017; 10(1): 61-71.

[18] Yazgi A, Degirmencioglu A. Optimisation of the seed spacing uniformity performance of a vacuum-type precision seeder using response surface methodology. Biosystems Engineering, 2007; 97(3): 347-356.

[19] Zhao Z, Li Y M, Chen J, Xu L Z. Numerical analysis and laboratory testing of seed spacing uniformity performance for vacuum-cylinder precision seeder. Biosystems Engineering, 2010; 106(4): 344-351.

[20] Yu J J, Liao Y T, Cong J L, Yang S, Liao Q X. Simulation analysis and match experiment on negative and positive pressures of pneumatic precision metering device for rapeseed. Int J Agric \& Biol Eng, 2014; 7(3): 1-12.

[21] Vianna L R, dos Reis A V, Machado A L T. Development of a horizontal plate meter with double seed outlets. Revista Brasileira De Engenharia Agricola E Ambiental, 2014; 18(10): 1086-1091.

[22] Khatchatourian O A, Binelo M O, de Lima R F. Simulation of soya bean flow in mixed-flow dryers using DEM. Biosystems Engineering, 2014; 123: 68-76.

[23] Yang L, He X T, Cui T, Zhang D X, Shi S, Zhang R, et al. Development of mechatronic driving system for seed meters equipped on conventional precision corn planter. Int J Agric \& Biol Eng, 2015; 8(4): 1-9.

[24] Liu H X, Guo L F, Fu L L, Tang S F. Study on multi-size seed-metering device for vertical plate soybean precision planter. Int J Agric \& Biol Eng, 2015; 8(1): 1-8.

[25] Zhang G Z, Zang Y, Luo X W, Wang Z M, Zhang Q, Zhang S S. Design and indoor simulated experiment of pneumatic rice seed metering device. Int J Agric \& Biol Eng, 2015; 8(4): 10-18. 